\title{
A Numerical Investigation on a Caloric Heat Pump Employing Nanofluids
}

\author{
Ciro Aprea ${ }^{1}$, Adriana Greco $^{2}$, Angelo Maiorino ${ }^{1}$, Claudia Masselli $^{1^{*}}$ \\ ${ }^{1}$ DIIn, University of Salerno, Via Giovanni Paolo II, 132 Fisciano (SA) 84084, Italy \\ ${ }^{2}$ DII, University of Naples “Federico II”, P.le Tecchio 80, Napoli 80125, Italy
}

Corresponding Author Email: cmasselli@unisa.it

https://doi.org/10.18280/ijht.370302

Received: 30 March 2019

Accepted: 31 May 2019

\section{Keywords:}

caloric, heat pump, nanofluids, solidstate, regenerator, energy performances

\begin{abstract}
Nowadays vapor compression is still the reference technique for heat pumping applications. There are Not-In-Kind heat pumping technologies where a prominent role is occupied by the ones based on solid-state refrigerants, called caloric. The name of such class of technologies comes from caloric effect, manifesting in caloric materials as temperature change due to an applied external field which changes its intensity adiabatically. The reference thermodynamical cycle is called Active Caloric Regenerative heat pump (ACR) cycle and it is applied to a caloric solid-state structure which is both refrigerant and regenerator. The structure is crossed by a Heat Transfer Fluid (HTF) (generally water) that transfers heat from the cold to the hot environment. This paper proposes optimizing solutions as nanofluids for enhancing the heat transfer. The energy performances of a caloric heat pump employing $\mathrm{Al}_{2} \mathrm{O}_{3}$-water nanofluids as HTF are evaluated through a 2-D model, for a wide set of caloric materials. The investigation reveals that the addition of nanofluids carries to an upgrade of the energy performances of the heat pump. The best combination occurs if the heat pump works with Ni-Ti (as refrigerant) and alumina-water nanofluid (10\% vol) as HTF.
\end{abstract}

\section{INTRODUCTION}

Nowadays vapor compression is still considered the reference technique for cooling and heat pumping applications $[1,2]$. Over the last 20 years vapor compression is going through years of profound renewal [3,4], due to the damages in terms of ozone depletion and global warming, provoked by the employment of fluid refrigerants [5-7]. Parallelly to the countermeasures adopted to limit the damage caused by vapor compression [8-13], alternative solutions to it are also being sought [14]. There are the cooling and heat pumping technologies, defined as Not-In-Kind [15, 16] where a prominent role is occupied by the class based on solid-state refrigerants, called caloric [17-20]. The name of such class of technologies comes from caloric effect: an intrinsic property of ferroic materials manifesting as temperature change due to an applied external field which changes its intensity adiabatically [21]. If the variation occurs isothermally, a total entropy change is detected in the material. These two variations are regulated by:

$$
\begin{array}{r}
\Delta s=\int_{Y_{0}}^{Y_{1}}\left(\frac{\partial X}{\partial T}\right)_{Y} d Y \\
\Delta T_{a d}=-\int_{Y_{0}}^{Y_{1}} \frac{T}{C}\left(\frac{\partial X}{\partial T}\right)_{Y} d Y
\end{array}
$$

The nature of the driving field Y particularizes the caloric effect. Magnetic fields applied to magnetocaloric materials give rise to magnetocaloric effect (MCE) [22, 23] where $\mathrm{Y}=\mathrm{H}$ and $\mathrm{X}=\mathrm{M}$, electric fields to electrocaloric effect (ECE) [24] where $\mathrm{Y}=\mathrm{E}$ and $\mathrm{X}=\mathrm{P}$, mechanical stress to elastocaloric effect (eCE) [25], where $\mathrm{Y}=\sigma$ and $\mathrm{X}=\varepsilon$, pressure field to barocaloric effect (BCE) [26] where $\mathrm{Y}=-\mathrm{p}$ and $\mathrm{X}=\mathrm{V}$.
The reference thermodynamical cycle of a caloric heat pump is called Active Caloric Regenerative heat pump (ACR) cycle and it is based on a Brayton cycle [27]. The ACR cycle is applied to a caloric solid-state structure which is both refrigerant and regenerator. The structure is placed between a cold and a hot heat exchanger and it is subjected to alternative cycles of intensity increasing/decreasing of the applied field. Therefore, the refrigerant has a solid-state but an auxiliary fluid (generally water or water-glycol mixture) is used to transfer the fluxes between the hot and the cold heat exchangers; thus, it is called Heat Transfer Fluid (HTF).

The four processes identifying the ACR cycle are the following:

1) adiabatic decreasing of the intensity of the external field applied to the caloric structure whom, consequently, cools down following caloric effect;

2) the cooled down caloric structure absorbs heat from the HTF that crosses it from the hot to the cold side.

3) adiabatic increasing of the intensity of the external field applied to caloric structure whom, as a consequence, heats up due to caloric effect;

4) the heat exchanged is pumped toward the environment by means of HTF flowing in the hot heat exchanger from the cold to the hot side of the regenerator. Indeed, the heat transfer fluid reaches the hot side (connected to the environment to be heat pumped) hotter than the medium temperature of the hot heat exchanger. Consequently, the fluid adduces heat toward the environment, and it realizes the desired effect of the ACR cycle for heat pumping.

As mentioned before, generally, the secondary heattransfer fluid is water or a water-ethylene mixture for subzero applications. Since the auxiliary fluid is responsible of the heat transferring in the regenerator from a side to another, 
optimizing solutions should be proposed for enhancing the heat transfer between the solid-state refrigerant and the fluid itself. One of these is constituted by nanofluids [28, 29].

Nanofluids are classified as new kind of heat transfer fluids; they are formed by common base fluids in which are dispersed solid-state nanoparticles due of high thermal conductivity. The nanoparticles, as the name suggests, present nanometric dimensions $(<100 \mathrm{~nm})$ and they could have metallic or non-metallic nature. The resulting fluid is a stable mixture of a base-fluid with nanoparticles, called nanofluid, due of enhanced thermal conductivity with respect to the starting base-fluid $[30,31]$. Nanofluids were presented for the first time to scientific community in 1995 by Choi [32] but, given the revolutionary discovered, they gained much attentions and all over the world scientists started to test nanofluids in the most varied applications [33-39].

As regards to solid-state refrigeration, very few have been studies on the application on nanofluids in the caloric systems and some of them are focused on magnetocaloric refrigeration [40-42]. The study on working with nanofluids in the other caloric-effects-based heat pumping systems is still an unexplored field, except the work proposed by Greco et al. [43] where the energy performances of a caloric heat pump employing $\mathrm{Al}_{2} \mathrm{O}_{3}+$ water nanofluids as $\mathrm{HTF}$ are evaluated. The present paper aims to expand the abovementioned analysis, evaluating the significative energy parameters. The investigation is perpetuated through a twodimensional model, previously experimentally validated [44, 45] with a rotary prototype [46, 47]. The tests were performed changing both the nanoparticle volume fraction of the nanofluids and the caloric materials, testing electrocaloric, elastocaloric and barocaloric candidates.

\section{THE STEPS OF THE INVESTIGATION}

This section aims to describe the salient steps of the investigation as: the choice of the caloric materials and the nanofluids; the description of the 2-D numerical tool employed for the investigation; the way the properties of the nanofluids and the caloric effect materials were modeled in the tool.

\subsection{Caloric solid-state refrigerants}

To select the caloric refrigerants for the present investigation we based on high-caloric effects and diversity criteria, in order to test the most performing ones, in room temperature range, among the electrocaloric, elastocaloric and barocaloric effect materials.

$\mathrm{Pb}_{0.97} \mathrm{La}_{0.02}\left(\mathrm{Zr}_{0.75} \mathrm{Sn}_{0.18} \mathrm{Ti}_{0.07}\right) \mathrm{O}_{3}$ (PLZST) [48], deposited on $\mathrm{LaNiO}_{3} / \mathrm{Si}(100)$ substrate, is the electrocaloric material under test. It exhibits a maximum Giant ECE at $278 \mathrm{~K}$ but $\Delta \mathrm{T}_{\text {ad }}$ remains very high in the range $278 \div 298 \mathrm{~K}$, making PLZST suitable for heat pump applications. Specifically, we considered it under electric field changes of $90 \mathrm{MV} \mathrm{m}^{-1}$ and $70 \mathrm{MV} \mathrm{m}^{-1}$ whose peaks of $\Delta \mathrm{T}_{\mathrm{ad}}$ are $54 \mathrm{~K}$ and $43 \mathrm{~K}$, respectively.

We also considered the elastocaloric Ni-Ti polycrystals [49], benchmark of elastocaloric systems, showing a peak at $350 \mathrm{~K}$ but anyway exhibiting a remarkable elastocaloric effect in temperature range devoted to heat pump applications. The considered stress field change is $0.9 \mathrm{GPa}$ which results in a peak of $25 \mathrm{~K}$ as adiabatic temperature change due to elastocaloric effect.

The barocaloric oxyfluorides $\left(\mathrm{NH}_{4}\right)_{2} \mathrm{MoO}_{2} \mathrm{~F}_{4}$ [50] showing a maximum direct barocaloric effect at $272 \mathrm{~K}$ which remains remarkable until $360 \mathrm{~K}$, ensures a good applicability for heat pumps operation mode. The considered drop of applied pressure field is $0.9 \mathrm{GPa}$ that guarantees a maximum of $18 \mathrm{~K}$ due to barocaloric effect.

As barocaloric we also focused on Acetoxy Silicone Rubber (ASR) exhibiting a supergiant [51] barocaloric effect investigated for $\Delta p=[0.273 ; 0.390] \mathrm{GPa}$ under which associated maximums $\Delta \mathrm{T}_{\mathrm{ad}}$ of 30 and $41 \mathrm{~K}$ occur, respectively.

\subsection{The heat transfer nanofluids}

In the present investigation the considered heat transfer fluids are the alumina-water nanofluids. They are composed of water, as base fluid, in which nanometric particles of alumina $\left(\mathrm{Al}_{2} \mathrm{O}_{3}\right)$ were dispersed.

Table 1 lists the properties of the base fluid and the nanoparticles of alumina-water nanofluids at $\mathrm{T}=293 \mathrm{~K}$ and $\mathrm{p}=1 \mathrm{~atm}$.

Table 1. Thermophysic properties of the base fluid the and nanoparticles of the alumina-water nanofluids

\begin{tabular}{ccccc}
\hline Substance & $\begin{array}{c}\boldsymbol{\rho} \\
\boldsymbol{k g}\end{array}$ & $\mathbf{C}$ & $\mathbf{k}$ & $\boldsymbol{\mu}$ \\
& {$\left[\frac{\boldsymbol{J}}{\boldsymbol{m}^{3}}\right]$} & {$\left[\frac{\boldsymbol{W}}{\boldsymbol{k g} \boldsymbol{K}}\right]$} & {$\left[\frac{\boldsymbol{k g}}{\boldsymbol{m} \boldsymbol{K}}\right]$} & {$\left[\frac{\boldsymbol{m s}}{\mathbf{m}}\right]$} \\
\hline Water & 998.2 & 4182 & 0.597 & $9.93 * 10^{-4}$ \\
$\mathrm{Al}_{2} \mathrm{O}_{3}$ & 3970 & 765 & 36 & - \\
\hline
\end{tabular}

The thermophysical properties of the nanofluids were evaluated through the following mathematical correlations available in open scientific literature [52-54]:

$$
\begin{array}{r}
\rho_{\mathrm{nf}}=(1-\varphi) \rho_{\mathrm{bf}}+\varphi \rho_{\mathrm{np}} \\
\rho_{\mathrm{nf}} C_{\mathrm{p}, \mathrm{nf}}=(1-\varphi)\left(\rho C_{\mathrm{p}}\right)_{\mathrm{bf}}+\varphi\left(\rho C_{\mathrm{p}}\right)_{\mathrm{np}} \\
\mu_{\mathrm{nf}}=\mu_{b f}(1+7.74 \varphi) \\
k_{n f}=k_{b f} \frac{k_{n p}+2 k_{b f}-2 \varphi\left(k_{b f}-k_{n p}\right)}{k_{n p}+2 k_{b f}+\varphi\left(k_{b f}-k_{n p}\right)}
\end{array}
$$

where, $\varphi$ is the volume fraction of the nanoparticles dispersed on equal volume of base fluid as:

$$
\varphi=\frac{V_{n p}}{V_{n f}}=\frac{m_{n p}}{m_{n f}}
$$

\subsection{The 2-D model of a caloric heat pump}

The behavior of a caloric heat pump is described through a 2-D model, already introduced [19] and validated experimentally in previous investigations [44, 45]. The geometry of the heat pump sees a parallel-plate regenerator made of caloric material, separated by channels in which the HTF crosses the regenerator. The desired effect is to add heat to the indoor room connected with a hot heat exchanger at $\mathrm{T}_{\mathrm{H}}$. The cold heat exchanger is coupled with the outdoor environment, whose temperature is $\mathrm{T}_{\mathrm{C}}$. Below there is the mathematical structure that the 2-D model is based on: 


$$
\begin{aligned}
& \left\{\begin{array}{c}
\frac{\partial u}{\partial x}+\frac{\partial v}{\partial y}=0 \\
\frac{\partial u}{\partial t}+u \frac{\partial u}{\partial x}+v \frac{\partial u}{\partial y}=-\frac{1}{\rho_{n f}} \frac{\partial p}{\partial x}+v\left(\frac{\partial^{2} u}{\partial x^{2}}+\frac{\partial^{2} u}{\partial y^{2}}\right) \\
\frac{\partial v}{\partial t}+u \frac{\partial v}{\partial x}+v \frac{\partial v}{\partial y}=-\frac{1}{\rho_{n f}} \frac{\partial p}{\partial y}+v\left(\frac{\partial^{2} v}{\partial x^{2}}+\frac{\partial^{2} v}{\partial y^{2}}\right) \\
\frac{\partial T_{n f}}{\partial t}+u \frac{\partial T_{n f}}{\partial x}+v \frac{\partial T_{n f}}{\partial y}=\frac{k_{f}}{\rho_{n f} C_{n f}}\left(\frac{\partial^{2} T_{n f}}{\partial x^{2}}+\frac{\partial^{2} T_{n f}}{\partial y^{2}}\right) \\
\frac{\partial T_{s}}{\partial t}=\frac{k_{s}}{\rho_{s} C_{s}}\left(\frac{\partial^{2} T_{s}}{\partial x^{2}}+\frac{\partial^{2} T_{s}}{\partial y^{2}}\right)
\end{array}\right. \\
& \left\{\begin{array}{c}
\rho_{n f} C_{n f} \frac{\partial T_{n f}}{\partial t}=k_{n f}\left(\frac{\partial^{2} T_{n f}}{\partial x^{2}}+\frac{\partial^{2} T_{n f}}{\partial y^{2}}\right) \\
\rho_{s} C_{s} \frac{\partial T_{s}}{\partial t}=k_{s}\left(\frac{\partial^{2} T_{S}}{\partial x^{2}}+\frac{\partial^{2} T_{s}}{\partial y^{2}}\right)+Q
\end{array}\right. \\
& Q=Q\left(\text { field }, T_{S}\right)=\frac{\rho_{S} C_{S}\left(\text { field }, T_{S}\right) \Delta T_{a d}\left(\text { field }, T_{S}\right)}{\tau}
\end{aligned}
$$

Eq. (8) models the fluid-flow processes of the ACR cycle; Eq. (9) describes the field rising/falling phases. Caloric effect is modeled through the Q-term reported in Eq. (10). It converts the caloric effect into a power density. Since Q is a function of the field and the temperature, its mathematical expression was obtained by a mathematical finder software, as a result of elaboration and manipulation of experimental data of $\mathrm{C}_{\mathrm{s}}$ (field, $\mathrm{T}_{\mathrm{s}}$ ) and $\Delta \mathrm{T}_{\mathrm{ad}}$ (field, $\mathrm{T}_{\mathrm{s}}$ ), coming from scientific literature. Different Q-terms correspond to the tested caloric materials.

The model is solved with Finite Element Method and the ACR cycle runs cyclically several times until reaching steady state that is satisfying the cyclicality criterion in every point the ACR regenerator:

$$
\delta=\max \{T(x, y, 0+n \theta)-T(x, y, 4 \tau+n \theta)\}<\bar{\varepsilon}
$$

\section{METHODOLOGY OF THE INVESTIGATION}

We tested the caloric materials introduced in section 2.1 as refrigerants of the active solid-state heat pump modelled by the 2-D model. The heat pump was supposed to work in the range $\mathrm{T}_{\mathrm{C}} \div \mathrm{T}_{\mathrm{H}}=278 \div 298 \mathrm{~K}$ at $1.25 \mathrm{~Hz}$ and $0.2 \mathrm{~m} \mathrm{~s}^{-1}$, respectively as ACR cycle and nanofluid velocity. The alumina-water nanofluid with nanoparticles volume fraction varied in the range $0 \div 10 \%$ was employed in the heat pump as heat transfer fluid.

The most significative energy performance carried out are introduced below.

An outstanding parameter is the ACR temperature span evaluated as:

$\Delta T_{\mathrm{ACR}}=\frac{1}{\tau} \int_{\tau+n \theta}^{2 \tau+n \theta} T_{\mathrm{nf}}(L, y, t) d t-\frac{1}{\tau} \int_{3 \tau+n \theta}^{4 \tau+n \theta} T_{\mathrm{nf}}(0, y, t) d t$

$\Delta T_{\mathrm{ACR}}$ is a parameter used to evaluate the maximum temperature drop across the ACR since it measures the temperature difference between the nanofluid exiting the regenerator at the hot side $(x=L)$ during the cold-to-hot flowing phase and at the cold side $(\mathrm{x}=0)$ during the hot-to cold flowing phase.

Another remarkable parameter is the power of the heat pump, that measures the power at which the system pumps heat:

$$
\dot{Q}_{\mathrm{H}}=\frac{1}{\theta} \int_{\tau+n \theta}^{2 \tau+n \theta} \dot{m}_{\mathrm{nf}} C_{\mathrm{nf}}\left(T_{\mathrm{nf}}(L, y, t)-T_{\mathrm{H}}\right) d t
$$

The Coefficient of Performance (COP) is conceived as the ratio between the heating power of the pump and the total energy spent to get it:

$$
C O P=\frac{\dot{Q}_{\mathrm{H}}}{\dot{W}_{\mathrm{TOT}}}=\frac{\dot{Q}_{\mathrm{H}}}{\dot{W}_{\text {field }}+\dot{W}_{\text {pump }}}
$$

$\dot{W}_{\text {TOT }}$ embraces both the contribution due to the external field variation ( $\dot{W}_{\text {field }}$ ) and the one connected to the mechanical power required for the fluid motion ( $\left.\dot{W}_{\text {pump }}\right)$, defined as follows:

$$
\begin{aligned}
& \dot{W}_{\text {field }}=\dot{Q}_{\mathrm{H}}-\dot{Q}_{\text {ref }} \\
& \dot{W}_{\text {pump }}=\frac{\dot{m}_{n f}\left(\Delta p_{C F}+\Delta p_{H F}\right)}{\eta_{p} \rho_{n f}}
\end{aligned}
$$

\section{RESULTS}

Basing on the methodology and the working conditions introduced in section 3, the most salient parameters to evaluate the energy performances of the caloric heat pump, were carried out and the results are reported in the present section.

Figure 1 reports the ACR temperature span as a function of nanoparticle volume fraction, for the set of the caloric materials tested. The results reveal that the highest temperature drops are proper of the electrocaloric PLZST for both the $\Delta \mathrm{E}$ considered. The absolute maximum is greater than $70 \mathrm{~K}$ and it has been detected when the regenerator works with PLZST under $\triangle \mathrm{E}=90 \mathrm{MV} \mathrm{\textrm {m } ^ { - 1 }}$ as solid-state refrigerant and with $\mathrm{Al}_{2} \mathrm{O}_{3}$-water nanofluid (10\% vol) as HTF. All the materials exhibiting a mechanocaloric effect (elastocaloric or barocaloric) present $\Delta \mathrm{T}_{\mathrm{ACR}}$ belonging to $30 \div 40 \mathrm{~K}$ range. Among them the best $\Delta \mathrm{T}_{\mathrm{ACR}}$ are the ones provided by ASR under $\Delta \mathrm{p}=390 \mathrm{GPa}$. The addiction of nanofluids brings to an increasing of ACR temperature span, with augmenting $\varphi$, for all the tested materials. A maximum increment of $+4.2 \%$ has been observed for the elastocaloric $\mathrm{NiTi}$, if the nanoparticle volume fraction of the aluminawater nanofluids grows from $0 \%$ up to $10 \%$. Considering globally the whole set of the caloric materials under test, the medium benefit registered if the regenerator works with nanofluids, in terms of $\Delta \mathrm{T}_{\mathrm{ACR}}$ is an increament of $+3.4 \%$.

Avoid writing long formulas with subscripts in the title; short formulas that identify the elements are fine (e.g., "NdFe-B").

Figure 2 shows the heating power of the caloric heat-pump for the tested materials occurring under the operative conditions of section 3 , when the heat-transfer fluid is alumina-water based nanofluid with variable concentration. General considerations arising through the examination of the data plotted are that $\dot{Q}_{\mathrm{H}}$ increases with $\varphi$ for all the tested materials. The medium benefit toward this parameter translates in a medium increment of $+19 \%$ if the system works with nanofluids. Specifically, PLZST under $\Delta E=90$ MV $\mathrm{m}^{-1}$ as well as NiTi under $\Delta \sigma=0.9 \mathrm{GPa}$ provide the highest $\dot{Q}_{\mathrm{H}}$ with a maximum settled around $580 \mathrm{~W}$ if the nanoparticle volume fraction of the alumina-water nanofluid is $10 \%$. This is due to the Giant ECE shown at $278 \mathrm{~K}$ by the 
former, and to the fact that elastocaloric effect is quite constant in the considered temperature range. On the contrary the lowest heating-powers are detected for $\left(\mathrm{NH}_{4}\right)_{2} \mathrm{MoO}_{2} \mathrm{~F}_{4}$ since they do not exceed $240 \mathrm{~W}$. Such results are due both to the $\Delta \mathrm{T}_{\mathrm{ad}}$ smaller than PLZST ones and to the peak located at $272 \mathrm{~K}$ (out of the working temperature range).

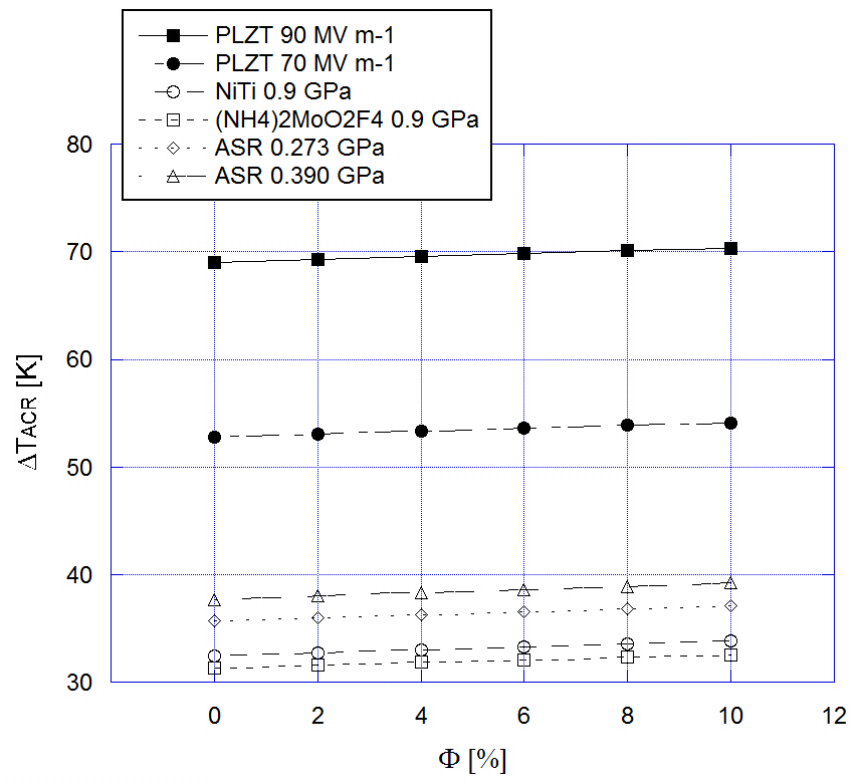

Figure 1. $\Delta \mathrm{T}_{\mathrm{ACR}}$ as a function of nanoparticles volume fraction, evaluated for the set of the caloric materials under test

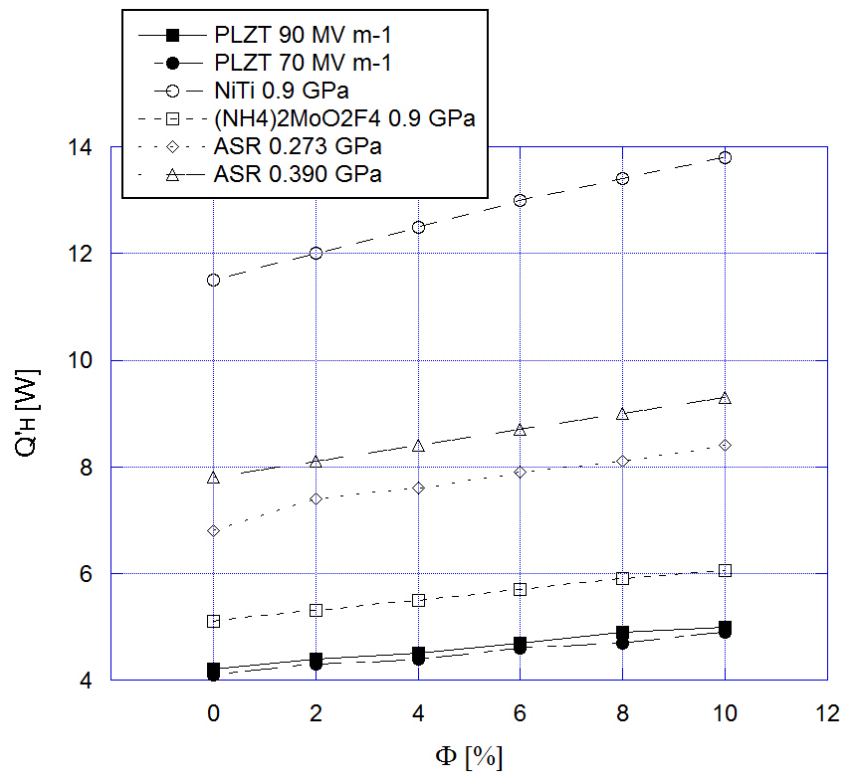

Figure 2. $\dot{Q}_{\mathrm{H}}$ as a function of nanoparticles volume fraction, evaluated for the set of the caloric materials under test

Figure 3 reports the coefficients of performances of the set of the caloric materials under test. COP has been reported with respect to the nanoparticle volume fraction of the alumina-water nanofluids. The situation is quite different from the data about heat-pumping powers, since the material with highest-COPs is still NiTi but not anymore PLZST. The latter exhibits, for both the $90 \mathrm{MV} \mathrm{m}^{-1}$ and $70 \mathrm{MV} \mathrm{m}^{-1}$ electric field variations, the lowest coefficients of performances of the set of tested materials. Such turnarounds are caused by the expenses needed for large electric field changing, resulting higher than mechanical stretching ones. The NiTi based caloric heat pump presents 14.8 as maximum COP, if it works with $10 \%$ alumina- $90 \%$ water nanofluid. A middle COP-increment of $+15 \%$ is detected if the nanofluid concentration increases from $0 \%$ up to $10 \%$. The barocaloric Acetoxy Silicone Rubber presents also satisfying COPs with a maximum of 9.3 registered for $\varphi=0.1$ under $\Delta p=0.39 \mathrm{GPa}$ and a middle increment of $+19 \%$ while increasing nanoparticle volume fraction.

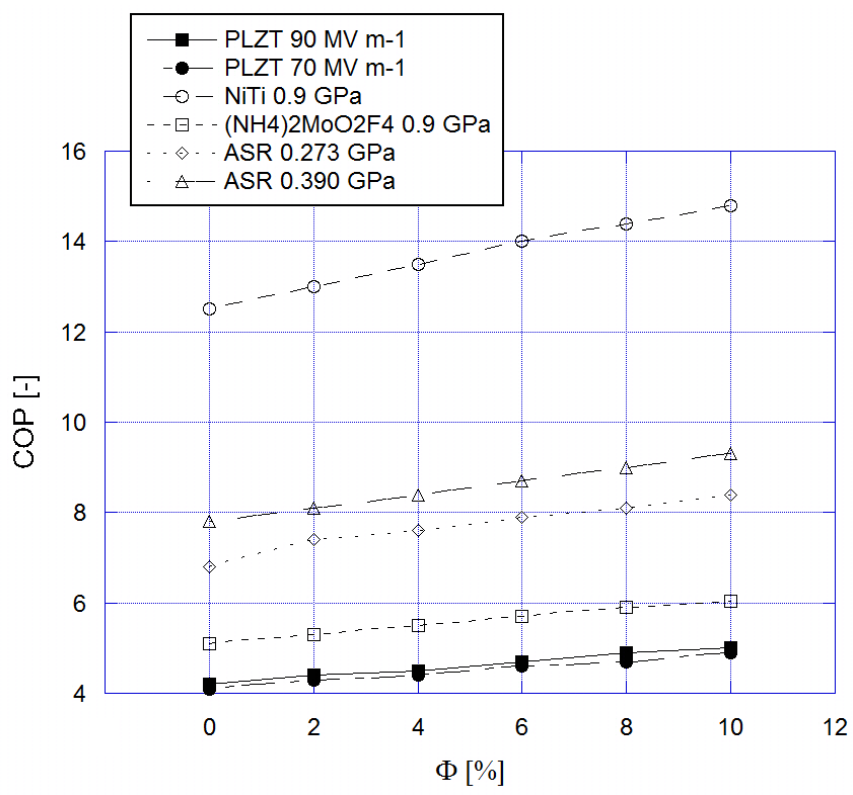

Figure 3. Coefficient of performance as a function of nanoparticles volume fraction, evaluated for the set of the caloric materials under test

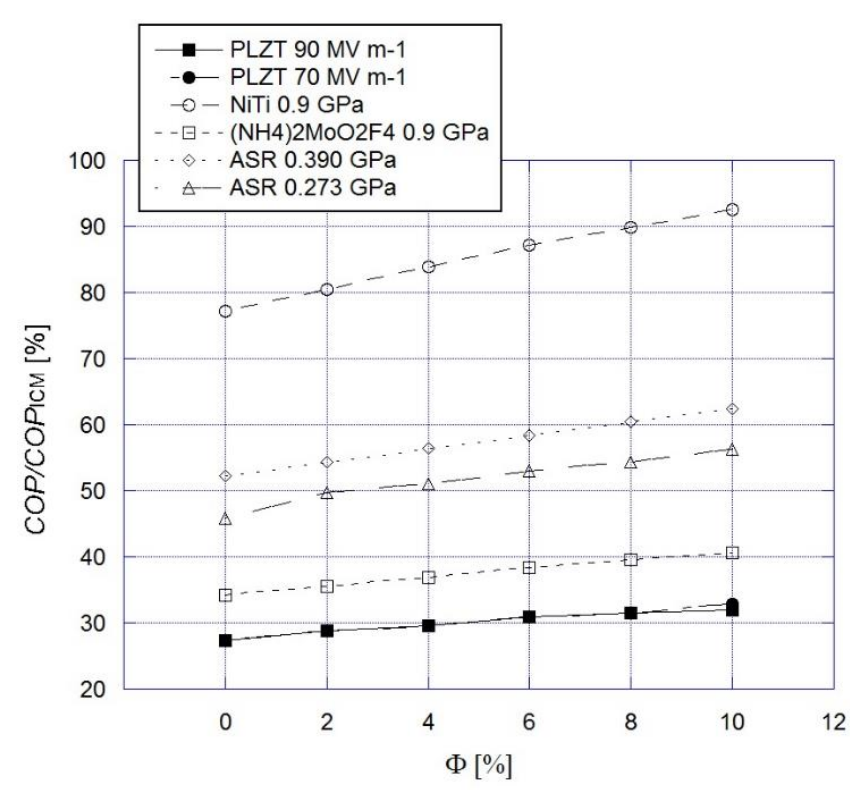

Figure 4. COP on Carnot COP as a function of nanoparticles volume fraction, evaluated for the set of the caloric materials under test

Furthermore, in Figure 4 the obtained coefficients of performance are compared to the Carnot COP. The material that comes closest to the Carnot COP is the elastocaloric NiTi with values mediumly around $85 \%$ of it. Specifically, 
the addiction of alumina-water nanofluids takes the COP of NiTi from $78 \%$ (with $\varphi=0$ ) up to $92 \%$ (with $\varphi=10 \%$ ).

On the contrary, due to the high expense required to generate the considered electric fields, the electrocaloric PLZST shows coefficients of performance just around $28 \%$ of ICM, with $\varphi=0$. Not even the employment of nanofluids leads to a significant increase, since the maximum $\mathrm{COP} / \mathrm{COP}_{\mathrm{ICM}}$ achieved is $35 \%$ (under $\varphi=10 \%$ ). Anyhow, as general comment, the addiction of nanofluids has a positive increment on the coefficients of performance of each material tested, that come closer to the $\mathrm{COP}_{\mathrm{ICM}}$ of $+20 \%$ (as average data) if $\varphi=10 \%$, with respect of the regenerator employing the base fluid as $\operatorname{HTF}(\varphi=0 \%)$.

\section{CONCLUSIONS}

This paper proposes optimizing solutions as nanofluids for enhancing the heat transfer. The energy performances of a caloric heat pump employing $\mathrm{Al}_{2} \mathrm{O}_{3}$-water nanofluids as $\mathrm{HTF}$ were evaluated through a 2-D model, for a wide set of caloric materials. The investigation reveals that the addition of nanofluids carries to an upgrade of the energy performances of the heat pump

In terms of $\Delta \mathrm{T}_{\mathrm{ACR}}$, the best performances are proper of the electrocaloric PLZST for both the $\Delta \mathrm{E}$ considered with an absolute maximum greater than $70 \mathrm{~K}$, detected under $\Delta \mathrm{E}=90 \mathrm{MV} \mathrm{m}^{-1}$ and $\varphi=10 \%$. Considering globally the whole set of the caloric materials under test, the medium benefit registered if the regenerator works with nanofluids, in terms of $\Delta \mathrm{T}_{\mathrm{ACR}}$ is an increment of $+3.4 \%$.

The highest heat pumping powers were noticed for PLZST under $\Delta \mathrm{E}=90 \mathrm{MV} \mathrm{m}^{-1}$ as well as NiTi under $\Delta \sigma=0.9 \mathrm{GPa}$. Considering the while set of tested materials, the medium benefit toward this parameter translates in a medium increment of $+19 \%$ if the system works with nanofluids.

The material with highest-COPs is still NiTi but not anymore PLZST, whose COPs are the lowest due to the high expense required for varying the intensity of the electric field. The material that comes closest to the Carnot COP is the elastocaloric NiTi with values mediumly around $85 \%$ of it. Anyhow, as general comment, the addiction of nanofluids has a positive increment on the coefficients of performance of each material tested, that come closer to the COP $\mathrm{ICM}_{\mathrm{ICM}}$ $+20 \%$ (as average data) if $\varphi=10 \%$, with respect of the regenerator employing the base fluid as $\operatorname{HTF}(\varphi=0 \%)$.

Therefore, basing on the results presented one can conclude that the best combination occurs if the caloric heat pump works with $\mathrm{Ni}$-Ti as refrigerant, and alumina-water nanofluid (10\% vol) as heat transfer fluid.

\section{REFERENCES}

[1] Moretti, E., Nassuato, L., Bordoni, G.P. (2019). Development of regression models to predict energy consumption in industrial sites: The case study of a manufacturing company in the central Italy. Tecnica Italiana - Italian Journal of Engineering Science, 63(24): 343-348. https://doi.org/10.18280/ti-ijes.632-433

[2] Ahamed, J.U., Saidur, R., Masjuki, H.H. (2011). A review on exergy analysis of vapor compression refrigeration system. Ren. and Sust. En. Rev., 15(3): 1593-1600. https://doi.org/10.1016/j.rser.2010.11.039
[3] Montreal Protocol on substances that deplete the ozone layer, United Nation Environment Program (UN), New York, NY, USA, 1987.

[4] Heath, E.A. (2017). Amendment to the Montreal protocol on substances that deplete the ozone layer (Kigali Amendment). Int. Legal Mater., 56(1): 193-205 https://doi.org/10.1017/ilm.2016.2

[5] Greco, A., Vanoli, G.P. (2005). Flow boiling heat transfer with HFC mixtures in a smooth horizontal tube. Part II: Assessment of predictive methods. Experimental Thermal and Fluid Science, 29(2): 199208.

https://doi.org/10.1016/j.expthermflusci.2004.03.004

[6] Calm, J.M., Didion, D.A. (1998). Trade-offs in refrigerant selections: past, present, and future. Int. J. of Refrig., 21(4): 308-321. https://doi.org/10.1016/S01407007(97)00089-3

[7] Greco, A., Mastrullo, R., Palombo, A. (1997). R407C as an alternative to R22 in vapour compression plant: An experimental study. Int. J. of En. Res., 21(12): 10871098. https://doi.org/10.1002/(SICI)1099114X(19971010)21:12<1087::AID-ER330>3.0.CO;2-Y

[8] Abas, N., Kalair, A.R., Khan, N., Haider, A., Saleem, Z., Saleem, M.S. (2018). Natural and synthetic refrigerants, global warming: A review. Ren. and Sust. En. Rev., 90: 557-569. https://doi.org/10.1016/j.rser.2018.03.099

[9] Aprea, C., Greco, A., Maiorino, A., Masselli, C., Metallo, A. (2016). HFO1234ze as drop-in replacement for R134a in domestic refrigerators: An environmental impact analysis. En. Proc., 101: 964-971. https://doi.org/10.1016/j.egypro.2016.11.122

[10] McLinden, M.O., Brown, J.S., Brignoli, R., Kazakov, A.F., Domanski, P.A. (2017). Limited options for lowglobal-warming-potential refrigerants. Nature Communications, $\quad 8: \quad 14476$ https://doi.org/10.1038/ncomms14476

[11] Aprea, C., Greco, A., Maiorino, A., Masselli, C., Metallo, A. (2016). HFO1234yf as a drop-in replacement for R134a in domestic refrigerators: A life cycle climate performance analysis. Int. J. of Heat and Techn., 34(2): S212-S218. https://doi.org/10.18280/ijht.34S204

[12] Bolaji, B.O., Huan, Z. (2013). Ozone depletion and global warming: Case for the use of natural refrigeranta review. Ren. and Sust. En. Rev., 18: 49-54. https://doi.org/10.1016/j.rser.2012.10.008

[13] Aprea, C., Greco, A., Maiorino, A., Masselli, C. (2018). The drop-in of HFC134a with HFO1234ze in a household refrigerator. Int. J. of Therm. Sc., 127: 117125. https://doi.org/10.1016/j.ijthermalsci.2018.01.026

[14] Brown, J.S., Domanski, P.A. (2014). Review of alternative cooling technologies. Appl. Therm. Eng., 64(1-2): 252-262.10. https://doi.org/1016/j.applthermaleng.2013.12.014

[15] Bansal, P., Vineyard, E., Abdelaziz, O. (2012). Status of not-in-kind refrigeration technologies for household space conditioning, water heating and food refrigeration. Int. J. of Sust. Built Env., 1(1): 85-101. https://doi.org/10.1016/j.ijsbe.2012.07.003

[16] Qian, S., Nasuta, D., Rhoads, A., Wang, Y., Geng, Y., Hwang, Y., Radermacher, R., Takeuchi, I. (2016). Notin-kind cooling technologies: A quantitative comparison of refrigerants and system performance. Int. J. of Refrig., 
62:

177-192.

https://doi.org/10.1016/j.ijrefrig.2015.10.019

[17] Aprea, C., Greco, A., Maiorino, A., Masselli, C. (2017). Electrocaloric refrigeration: an innovative, emerging, eco-friendly refrigeration technique. J. of Phys.: Conf. Ser., 796(1): 012019. https://doi.org/10.1088/17426596/796/1/012019

[18] Kitanovski, A., Plaznik, U., Tomc, U., Poredoš, A. (2015). Present and future caloric refrigeration and heatpump technologies. Int. J. of Refrig., 57: 288-298. https://doi.org/10.1016/j.ijrefrig.2015.06.008

[19] Aprea, C., Greco, A., Maiorino, A., Masselli, C. (2018). Solid-state refrigeration: A comparison of the energy performances of caloric materials operating in an active caloric regenerator. Energy, 165: 439-455. https://doi.org/10.1016/j.energy. 2018.09.114

[20] Greco, A. Aprea, C., Maiorino, A., Masselli, C. (2019). A review of the state of the art of the solid-state caloric cooling processes at room-temperature before 2019. Int. J. of $\quad$ Refrig., 106 : https://doi.org/10.1016/j.ijrefrig.2019.06.034

[21] Fähler, S., Rößler, U. K., Kastner, O., Eckert, J., Eggeler, G., Emmerich, H., Entel P., Müller S., Quandt E., Albe, K. (2012). Caloric effects in ferroic materials: New concepts for cooling. Adv. Eng. Mat., 14(1-2): 1019. https://doi.org/10.1002/adem.201100178

[22] Aprea, C., Greco, A., Maiorino, A. (2013). The use of the first and of the second order phase magnetic transition alloys for an AMR refrigerator at room temperature: A numerical analysis of the energy performances. En. Conv. and Man., 70: 40-55. https://doi.org/10.1016/j.enconman.2013.02.006

[23] Aprea, C., Greco, A., Maiorino, A., Masselli, C. (2015). A comparison between rare earth and transition metals working as magnetic materials in an AMR refrigerator in the room temperature range. Appl. Therm. Eng., 91: 767-777.

https://doi.org/10.1016/j.applthermaleng.2015.08.083

[24] Aprea, C., Greco, A., Maiorino, A., Masselli, C. (2017). A comparison between electrocaloric and magnetocaloric materials for solid state refrigeration. Int. J. of Heat and Techn., 35(1): 225-234. https://doi.org/10.18280/ijht.350130

[25] Tušek, J., Engelbrecht, K., Millán-Solsona, R., Mañosa, L., Vives, E., Mikkelsen, L.P., Pryds, N. (2015). The elastocaloric effect: A way to cool efficiently. Adv. En. Mat., 5(13). https://doi.org/10.1002/aenm.201500361

[26] Strässle, T., Furrer, A., Dönni, A., Komatsubara, T. (2002). Barocaloric effect: The use of pressure for magnetic cooling in Ce3Pd20Ge6. J. of Appl. Phys., 91(10): 8543-8545. https://doi.org/10.1063/1.1456450

[27] Gómez, J.R., Garcia, R.F., Catoira, A.D.M., Gómez, M.R. (2013). Magnetocaloric effect: A review of the thermodynamic cycles in magnetic refrigeration. Ren. and Sust. En. Rev., 17: 74-82. https://doi.org/10.1016/j.rser.2012.09.027

[28] Saidur, R., Leong, K.Y., Mohammad, H. (2011). A review on applications and challenges of nanofluids. Ren. and Sust. En. Rev., 15(3): 1646-1668. https://doi.org/10.1016/j.rser.2010.11.035

[29] Kumar D., Sokhal G.S., Sharma P. (2019). Numerical analysis of the heat and fluids flow performance of $\mathrm{CuO}$-nanofluids in flat tube with bend. Revue des
Composites et des Materiaux Avances, 29(1): 63-69. https://doi.org/10.18280/rcma.290110

[30] Choi, S.U.S., Zhang, Z.G., Yu, W., Lockwood, F.E., Grulke, E.A. (2001). Anomalously thermal conductivity enhancement in nanotube suspensions. Appl. Phys. Lett., 79: 2252-2254. https://doi.org/10.1063/1.1408272

[31] Alirezaie, A., Hajmohammad, M.H., Alipour, A. (2018) Do nanofluids affect the future of heat transfer? A benchmark study on the efficiency of nanofluids. Energy, 157: 979-989. https://doi.org/10.1016/j.energy.2018.05.060

[32] Choi, S.U.S. (1995). Enhancing thermal conductivity of fluids with nanoparticles. Developments and Applications of Non-Newtonian Flows, FED, 231/MD 66: 99-105.

[33] Sharafeldin, M.A., Gróf, G., Mahian, O. (2017). Experimental study on the performance of a flat-plate collector using WO3/Water nanofluids. Energy, 141: 2436-2444. https://doi.org/10.1016/j.energy.2017.11.068

[34] Abadeh, A., Rejeb, O., Sardarabadi, M., Menezo, C., Passandideh-Fard, M., Jemni, A. (2018). Economic and environmental analysis of using metal-oxides/water nanofluid in photovoltaic thermal systems (PVTs). Energy, 159: 1234-1243. https://doi.org/10.1016/j.energy.2018.06.089

[35] Manikandan, S., Rajan, K.S. (2016). Sand-propylene glycol-water nanofluids for improved solar energy collection. $\quad$ Energy, 113: 917-929. https://doi.org/10.1016/j.energy.2016.07.120

[36] Krishnan, R.Y., Manikandan, S., Suganthi, K.S., Vinodhan, V.L., Rajan, K.S. (2016). Novel copperPropylene glycol nanofluid as efficient thermic fluid for potential application in discharge cycle of thermal energy storage. Energy, 107: 482-492. https://doi.org/10.1016/j.energy.2016.04.047

[37] Kazemi-Beydokhti, A., Heris, S.Z. (2012). Thermal optimization of combined heat and power (CHP) systems using nanofluids. Energy, 44(1): 241-247. https://doi.org/10.1016/j.energy.2012.06.033

[38] Garoosi, F., Hoseininejad, F., Rashidi, M.M. (2016). Numerical study of natural convection heat transfer in a heat exchanger filled with nanofluids. Energy, 109: 664-678. https://doi.org/10.1016/j.energy.2016.05.05

[39] Chandrasekaran, P., Cheralathan, M., Kumaresan, V., Velraj, R. (2014). Enhanced heat transfer characteristics of water based copper oxide nanofluid PCM (phase change material) in a spherical capsule during solidification for energy efficient cool thermal storage system. $\quad$ Energy, 62: 636-642. https://doi.org/10.1016/j.energy.2014.05.089

[40] Chiba, Y. (2017). Enhancements of thermal performances of an active magnetic refrigeration device based on nanofluids. Mechanics, 23(1): 31-38. https://doi.org/10.5755/j01.mech.23.1.13452

[41] Mugica, I., Roy, S., Poncet, S., Bouchard, J., Nesreddine, H. (2017). Exergy analysis of a parallelplate active magnetic regenerator with nanofluids. Entropy, 19(9): 464. https://doi.org/10.3390/e19090464

[42] Greco, A., Aprea, C., Maiorino, A., Masselli, C. (2019). On the utilization of nanofluids as secondary fluid for heat transfer in a magnetocaloric cooler. Tecnica Italiana - Italian Journal of Engineering Science, 63(1): 52-58. https://doi.org/10.18280/ti-ijes.630107 
[43] Greco, A., Aprea, C., Maiorino, A., Masselli, C. (2019). Nanofluids as heat transfer fluids for high-efficiency caloric heat pumps. Tecnica Italiana - Italian Journal of Engineering Science, 63(2-4): 251-256. https://doi.org/10.18280/ti-ijes.632-419

[44] Aprea, C., Cardillo, G., Greco, A., Maiorino, A., Masselli, C. (2015). A comparison between experimental and 2D numerical results of a packed-bed active magnetic regenerator. Appl. Therm. Eng., 90: 376-383.

https://doi.org/10.1016/j.applthermaleng.2015.07.020

[45] Aprea, C., Greco, A., Maiorino, A., Masselli, C. (2018). Energy performances and numerical investigation of solid-state magnetocaloric materials used as refrigerant in an active magnetic regenerator. Therm. Sc. and Eng. Progr., 6: 370-379. https://doi.org/10.1016/j.tsep.2018.01.006

[46] Aprea, C., Cardillo, G., Greco, A., Maiorino, A., Masselli, C. (2016). A rotary permanent magnet magnetic refrigerator based on AMR cycle. Appl. Therm. Eng., 101: 699-703. https://doi.org/10.1016/j.applthermaleng.2016.01.097

[47] Aprea, C., Greco, A., Maiorino, A. (2017). An application of the artificial neural network to optimise the energy performances of a magnetic refrigerator. Int. J. of Refrig., 82: 238-251. https://doi.org/10.1016/j.ijrefrig.2017.06.015

[48] Zhao, Y., Hao, X., Zhang, Q. (2015). A giant electrocaloric effect of a $\mathrm{Pb} 0.97 \mathrm{La} 0.02$ ( $\mathrm{Zr} 0.75 \mathrm{Sn}$ $0.18 \mathrm{Ti} 0.07) \mathrm{O} 3$ antiferroelectric thick film at room temperature. J. of Mat. Chem. C, 3(8): 1694-1699. https://doi.org/10.1039/C4TC02381A

[49] Tušek, J., Engelbrecht, K., Millán-Solsona, R., Mañosa, L., Vives, E., Mikkelsen, L.P., Pryds, N. (2015). The elastocaloric effect: A way to cool efficiently. Adv. En. Mat., $5(13)$ :

1500361 https://doi.org/10.1002/aenm.201500361

[50] Gorev, M.V., Bogdanov, E.V., Flerov, I.N., Kocharova, A.G., Laptash, N.M. (2010). Investigation of thermal expansion, phase diagrams, and barocaloric effect in the (NH 4) 2 WO 2 F 4 and (NH 4) 2 MoO 2 F 4 oxyfluorides. Phys. of the Sol. St., 52(1): 167-175. https://doi.org/10.1134/S106378341

[51] Imamura, W., Usuda, E.O., Paixão, L.S., Bom, N.M., Gomes, A.M., Carvalho, A.M.G. (2017). Supergiant barocaloric effects in acetoxy silicone rubber around room temperature. arXiv preprint arXiv:1710.01761

[52] Bianco, V., Vafai, K., Manca, O., Nardini, S. (2015). Heat transfer enhancement with nanofluids. CRC Press. https://doi.org/10.1201/b18324

[53] Brinkman, H.C. (1952). The viscosity of concentrated suspensions and solutions. The J. of Chemic. Phys., 20(4): 571. https://doi.org/10.1063/1.1700493

[54] Hamilton, R.L., Crosser, O.K. (1962) Thermal conductivity of heterogeneous two-component systems.

Ind. \& Eng. Chemis. Fund., 1(3): 187-191. https://doi.org/10.1021/i160003a005

\section{NOMENCLATURE}

C

$\mathrm{E}$

$\mathrm{H}$

$\mathrm{k}$

$\mathrm{L}$

$\mathrm{M}$

$\mathrm{m}$

Q

Q

V

W

$\mathrm{X}$

$\mathrm{X}$

Y

$\mathrm{y}$

\section{Greek symbols}

$\Delta$

$\varepsilon$

$\theta$

$\mu$

$v$

$\varphi$

$\sigma$

$\tau$

\section{Subscripts}

0

1

ad

bf

$\mathrm{C}$

$\mathrm{H}$

ICM

nf

np

$\mathrm{p}$

$\mathrm{s}$

TOT specific heat, $\mathrm{J} \mathrm{kg}^{-1} \cdot \mathrm{K}^{-1}$

electric field, V.m ${ }^{-1}$

magnetic field, A. $\mathrm{m}^{-1}$

thermal conductivity, W. $\mathrm{m}^{-1} \cdot \mathrm{K}^{-1}$

length of the regenerator, $\mathrm{m}$

magnetization, A. $\mathrm{m}^{-1}$

mass, $\mathrm{kg}$

polarization C. $\mathrm{m}^{-2}$

pressure, $\mathrm{Pa}$

power density, W. $\mathrm{m}^{-3}$

power, W

entropy, $\mathrm{J}^{\mathrm{kg}^{-1}}$. $\mathrm{K}^{-1}$

temperature, $\mathrm{K}$

time, $\mathrm{s}$

longitudinal fluid velocity, $\mathrm{m} . \mathrm{s}^{-1}$

volume, $\mathrm{m}^{3}$

orthogonal fluid velocity, $\mathrm{m} . \mathrm{s}^{-1}$

mechanical power, $\mathrm{W}$

conjugate field

longitudinal spatial coordinate, $\mathrm{m}$

applied driving field

orthogonal spatial coordinate, $\mathrm{m}$

finite difference

elongation, $\%$

period of ACR cycle, $s$

dynamic viscosity, $\mathrm{kg} \cdot \mathrm{m}^{-1} \cdot \mathrm{s}^{-1}$

cinematic viscosity, $\mathrm{m}^{+2} \cdot \mathrm{s}^{-1}$

nanofluid concentration

density, kg. $\mathrm{m}^{-3}$

stress, $\mathrm{Pa}$

period of each step of ACR cycle, $s$

initial

final

adiabatic

base fluid

cold

Hot

Inverse Carnot Machine

nanofluid

nanoparticles

constant pressure

solid

total 